\title{
A BUROCRACIA CORDIAL: A IMPLANTAÇÃO DA ESTRATÉGIA DE APOIO INSTITUCIONAL NA POLÍTICA NACIONAL DE ATENÇÃO BÁSICA EM SAÚDE
}

\author{
THE CORDIAL BUREAUCRACY:THE IMPLEMENTATION OF THE INSTITUTIONAL \\ SUPPORT STRATEGY IN THE NATIONAL PRIMARY HEALTH CARE POLICY
}

Felipe Rangel de Souza Machado ${ }^{1}$ (D) (0000-0002-5028-8888), Francini Lube Guizardi² iD) (0000-0002-5086-4128), Ana Sílvia Pavani Lemos² (D) (0000-0002-2483-4347)

${ }^{1}$ Fundação Oswaldo Cruz, Escola Nacional de Saúde Pública Sergio Arouca, Departamento de Direitos Humanos, Saúde e Diversidade Cultural, Rio de Janeiro, RJ, Brasil. <felipersmachado@gmail.com>

${ }^{2}$ Fundação Oswaldo Cruz, Escola de Governo, Laboratório de Educação, Mediações Tecnológicas e Transdisciplinaridade em Saúde, Brasília, DF, Brasil.

Resumo O artigo analisa o papel dos apoiadores institucionais como sujeitos responsáveis pela condução das políticas públicas. Busca, desse modo, compreender a forma de construção de relações institucionais desde a base do Estado brasileiro, mediante ao estabelecimento de dinâmicas relacionais entre agentes públicos, especialmente no enfrentamento das complexas questões sobre as relações federativas brasileiras. O estudo foi realizado na Coordenação Geral de Gestão da Atenção Básica, do Departamento de Atenção Básica do Ministério da Saúde. Configura uma pesquisa ancorada na epistemologia qualitativa, com a realização de pesquisa documental, observação, entrevistas em profundidade e grupos focais entre novembro de 2015 e junho de 2017. Os resultados permitiram a identificação de dois elementos estruturantes do trabalho dos apoiadores - vínculo e conhecimento do território -, os quais subsidiaram a construção de uma tipologia da estratégia de atuação desenvolvida e operada pelos apoiadores, a saber: aplicação, adaptação e cooperação. Conclui-se que o avanço da implantação da estratégia de apoio institucional foi possível fundamentalmente em função da dinâmica relacional e presencial entre sujeitos, e seus resultados indicam possibilidades concretas de avanço na garantia do direito à saúde, não obstante as dificuldades e contradições que caracterizam o federalismo brasileiro.

Palavras-chave atenção primária de saúde; gestão em saúde; organização e administração; federalismo; burocracia.
Abstract Thise article analyzes the role of the institutional supporters as individuals responsible for the conduction of public policies. Thus, it aims to understand the way in which institutional relationships are developed from the basis of the Brazilian State, through the establishment of relational dynamics among public agents, especially in the confrontation of complex issues regarding Brazilian federative relationships. The study was conducted at the General Coordination for Primary Health Care Management of the Primary Health Care Department of the Brazilian Ministry of Health. The research was based on qualitative epistemology, with the development of a documentary research, observation, in-depth interviews and focus groups between November 2015 and June 2017. The results enabled the identification of two structuring elements of the work of the supporters - ties to and knowledge of the territory -, which subsidize the development of a typology of the strategy of action developed and operated by the supporters, namely: application, adaptation, and cooperation. We concluded that the advancement in the implementation of the institutional support strategy was fundamentally made possible due to the relational and in-person dynamics among the individuals, and its results indicate concrete possibilities regarding the advancement in the guarantee of the right to health, in spite of the difficulties and contradictions that characterize Brazilian federalism.

Keywords primary health care; management in health; organization and administration; federalism; bureaucracy. 


\section{Introdução}

O Ministério da Saúde (MS), desde 2011, implementou estratégias voltadas para a transformação do padrão histórico de conformação das relações federativas no Brasil, buscando responder à complexidade da gestão de um sistema universal de saúde, num país de dimensões continentais. Este movimento orientava-se para a democratização e a qualificação técnica da saúde pública, premissas que justificaram a incorporação da função apoio institucional (AI) como tecnologia de intervenção na organização do trabalho em saúde. $\mathrm{O}$ referencial teórico metodológico que embasa o AI parte da compreensão de que a gestão se exerce entre sujeitos, ainda que disponham de diferentes recursos de poder, motivo pelo qual é, necessariamente, uma gestão compartilhada. Desta forma, com base na noção de cogestão, o AI busca reconfigurar mecanismos hegemônicos do campo da administração, em especial, os modos instituídos de coordenação, planificação, supervisão e avaliação do trabalho, visando ampliar a democracia nas instituições de saúde (Campos, 1998; Campos, 2005; Oliveira, 2011).

O AI foi inicialmente formulado por Gastão Wagner de Sousa Campos, em sua tese de livre docência, por meio da articulação de referenciais e conceitos advindos dos campos da administração, saúde coletiva, pedagogia e psicanálise, com destaque para o enfoque da Análise Institucional de tradição francesa. As primeiras experiências de AI no Sistema Único de Saúde (SUS) ocorreram no início da década de 2000, em âmbito municipal, ganhando abrangência nacional nas políticas de saúde depois de 2003, com a inclusão do referencial na Política Nacional de Humanização (PNH), na Política Nacional de Educação Permanente em Saúde (PNEPS), e nas ações empreendidas pelo Departamento de Apoio à Descentralização, vinculado à Secretaria Executiva do Ministério da Saúde (DAD/MS).

Em 2011, o AI entrou na agenda da política de saúde como um recurso para reconfigurar os modos de ação das diferentes secretarias do MS. Esta reorganização buscou, sobretudo, intervir nas relações interfederativas, tendo em vista o objetivo de viabilizar a agenda estratégica da instituição.

Nesse período, emerge a concepção de um apoio integrado, tendo como pano de fundo o contexto de implementação dos dispositivos do decreto $\mathrm{n}$. 7.508, de 2011, que regulamenta da lei n. 8.080/90. O apoio integrado foi formulado com o objetivo de promover um federalismo cooperativo, baseado na compreensão da interdependência requerida pela coordenação das atividades e responsabilidades governamentais no campo da saúde. Estes aspectos se revelaram estratégicos para avançar na regionalização do sistema de saúde, um desafio permanente, que diferentes recursos político-normativos, como a 
Norma Operacional da Assistência à Saúde (2001) e o Pacto pela Saúde (2006) não conseguiram fazer avançar de forma substancial.

Deste modo, tal orientação resulta de um processo político que teve como marco o Pacto Pela Saúde, instituído em 2006 como um movimento de reforma institucional acordado entre as três esferas de gestão do SUS. O pacto resultou de um debate crítico sobre a relação federativa estabelecida no processo de consolidação do SUS, que evidenciou um conjunto de problemas relacionados à concentração normativa e financeira na instância federal, e nas derivações hierárquicas e nas demais implicações institucionais que esse padrão instituiu como modo de gestão hegemônico no SUS. Tendo pretendido promover inovações nos processos e instrumentos de gestão, com base em uma aposta contratualista, o movimento gerado pelo pacto não logrou reverter a tendência histórica de centralização no governo federal, muito embora tenha alcançado uma série de resultados positivos, como a definição de uma agenda de prioridades, objetivos e metas compartilhadas; a reorganização dos mecanismos de financiamento; e a instituição dos colegiados regionais de gestão.

Considerado este contexto, em que o tema das relações federativas ganhou destacada evidência com o Pacto pela Saúde, o apoio integrado foi formulado com o objetivo de fortalecer a gestão do SUS, também ancorado no reconhecimento dos limites das práticas tradicionais de indução financeira e condução normativa. A metodologia proposta foi articulada em torno de dois principais objetivos: instituir novos modos de relação interfederativa, baseados na pactuação solidária das responsabilidades governamentais; e enfrentar a profunda fragmentação institucional, presente tanto no sistema de saúde, quanto, de forma interna ao próprio ministério, nos modos de ação de seus setores específicos.

A operacionalização da estratégia previa a configuração de equipes estaduais de apoio integrado, que atuariam como referência para os gestores locais e regionais no SUS no diálogo com o MS. Tais equipes seriam formadas por dois grupos: apoiadores generalistas, provindos das secretarias que possuem políticas de saúde estruturantes para o SUS (Secretaria de Atenção à Saúde (SAS), Secretaria de Gestão Estratégica e Participativa (SGEP), Secretaria de Gestão da Educação e do Trabalho em Saúde) e a elas diretamente vinculados; e apoiadores temáticos, portadores de saberes especializados em determinados processos de atenção e gestão, vinculados às redes temáticas prioritárias, que constituíam então objetivos estratégicos de governo (rede cegonha, rede de urgência e emergência e rede de atenção psicossocial, com ênfase no enfrentamento do crack e outras drogas).

É nesse contexto, entre autonomia e necessidade de interação entre os entes federados, entre as especificidades de cada secretaria do MS e a necessidade de diminuir a fragmentação na implementação das políticas de saúde, 
entre a agenda estratégica do SUS e a singularidade dos contextos locais, que se insere a discussão da estratégia do AI no SUS, desde 2011. Trata-se de uma aposta na possibilidade de promover maior horizontalidade nas relações interfederativas, maior cooperação na construção das Redes de Atenção à Saúde nas Regiões de Saúde, contratualizando o desenvolvimento das práticas de atenção e gestão, que produzem acolhimento, com ampliação do acesso e da qualidade no SUS (Brasil, 2011, p. 7).

A diferença que essa aposta representa consiste na configuração de um novo lugar e um novo papel institucional de mediação no processo político de implementação das políticas de saúde. Por um lado, uma mediação em que os apoiadores representam o governo federal na relação direta com os demais gestores do SUS; por outro lado, uma mediação orientada para a construção de objetivos comuns entre os setores do MS. Desde este lugar de mediação, o apoiador institucional deve, idealmente, dialogar com as realidades e especificidades locais, para além das normas e da indução financeira (Brasil, 2011, p. 17), promovendo um aprendizado institucional capaz de contribuir para aprimorar a prática gestora dos atores e coletivos envolvidos.

Entendemos a função "Apoio", no âmbito do MS, como o papel institucional exercido por seu agente (aqui chamado de apoiador), na articulação federativa, que assume o posicionamento subjetivo, técnico, pedagógico, ético e político de acordo com os objetivos estratégicos da gestão federal e a metodologia de Apoio Integrado, aqui explicitada, e as demandas e/ou necessidades dos Estados e Municípios (Brasil, 2013, p.14. Grifo do autor).

Neste desenho, conformou-se também uma diferenciação entre apoiadores centralizados e apoiadores descentralizados, ambos vinculados às diferentes políticas do MS. Os primeiros residiam em Brasília e atuavam no MS, em atividades internas de gestão, complementadas por ações de caráter pontual nos estados e municípios, orientadas para a implementação de políticas e programas de saúde. Por sua vez, os apoiadores descentralizados residiam e trabalhavam in loco, ocupando-se da articulação, intervenção e acompanhamento das políticas de saúde nos territórios.

\section{Delimitação do objeto de pesquisa}

No presente estudo, voltamo-nos para atuação dos apoiadores vinculados à Coordenação Geral de Gestão da Atenção Básica (CGGAB), do Departamento de Atenção Básica (DAB) do MS responsável pela condução da estratégia do apoio institucional na implementação da Política Nacional de Atenção Básica (PNAB). Ressalta-se que o enfoque analítico do presente artigo não busca apreender a especificidade da prática do AI no contexto da Atenção Primária 
em Saúde (APS), ou analisar seus efeitos no curso histórico e institucional da PNAB. A escolha deste objeto empírico decorreu, antes, de suas características típicas para o objetivo proposto, dada a intensa e capilarizada relação entre os três entes federados, decorrentes do papel da Atenção Básica (AB) no sistema de saúde. Nesse sentido, consiste em uma amostra típica, de caráter intencional, conforme descrito por Deslauriers e Kérisit (2014).

$\mathrm{O}$ artigo apresenta parte dos resultados da pesquisa intitulada “Apoio Institucional na Atenção Básica em Saúde: estudo sobre democratização e gestão pública", financiada por meio da Chamada Universal MCTI/CNPq n.14, de 2014, e tem como foco o papel dos apoiadores institucionais no enfrentamento das complexas questões que envolvem as relações federativas brasileiras.

Assim, no que tange à construção conceitual do problema de pesquisa, compreendemos que a incorporação do apoio institucional compôs um contexto, no tocante à configuração do Estado brasileiro, em que a preocupação com a democratização da gestão pública revelou avanços no governo Dilma Rousseff (2011-2016). Dentre os aspectos que nos permitem fazer tal afirmação, a despeito de muitas contradições que marcaram a configuração da base governista e seus reflexos na ação do executivo federal, podemos destacar a criação da Lei de Acesso à Informação (Lei n. 12.527 de 2011), a qual garante a qualquer cidadão o direito à informação dos órgãos e entidades públicos. Três anos depois, em 2014, foi editado o Decreto n. 8.243, que criava a Política Nacional de Participação Social para atuar em diversas políticas sociais. O decreto durou pouco tempo, tendo sido derrubado pelo parlamento, que explicitamente repudiou qualquer tentativa de ampliação dos mecanismos da democracia direta no Brasil. É preciso também pontuar que, de modo associado aos movimentos em direção à democratização do Estado, uma perspectiva gerencial de administração pública ganhou relevo no governo e interferiu na conformação de várias de suas políticas e programas, principalmente aqueles alçados à condição de estratégicos.

Além disso, no momento de escrita deste artigo, foi publicado o Decreto Presidencial n. 9.690, de 2019, que altera a lei de acesso à informação e amplia aqueles que podem definir uma informação como sigilosa. Certamente, um imenso retrocesso na democratização do Estado brasileiro, o qual reforça o fato de que as ressalvas dos grupos políticos dominantes, no cenário nacional, em relação à democratização da esfera pública têm sido a força central na manutenção da percepção peculiar, apontada por Jessé Souza (2015, p. 32), de que o Estado e suas ações são sempre incompetentes e inconfiáveis. Este não é, certamente, o pressuposto deste trabalho. Ao contrário.

Nesse sentido, certamente o caráter indutor do MS no SUS (Baptista, 2007), com base no financiamento, permanece sendo fundamental, entretanto, partimos aqui do questionamento sobre de que forma essa indução se materializou nesta experiência específica, dada a aposta na construção de 
um federalismo cooperativo. Tal interrogação indica-nos a necessidade de aprofundamento na análise teórica, associando a discussão sobre federalismo na saúde com o papel dos sujeitos na condução das políticas públicas, a fim de apreender as práticas e relações sociais que permeiam e produzem efeitos para além da normatividade das portarias ministeriais. Diversos estudos têm se dedicado a compreender o papel da burocracia na efetivação de políticas e reconhecido o papel fundamental desempenhado pelos 'burocratas', entendidos como o "corpo de funcionários que atuam dentro do Estado" (Lotta e Santiago, 2017, p. 23).

Esses autores lembram que "existe uma grande distância entre os objetivos e o desenho concebidos originalmente pelos formuladores e suas traduções enquanto políticas públicas" (Lotta e Santiago, 2017, p. 27). Além disso, "esses burocratas são um elo fundamental entre as regras e sua aplicação prática, entre o mundo da política e o implementador que se relaciona com o usuário, entre as múltiplas agências e seus entendimentos para construção de consensos em torno das políticas públicas" (Lotta, Pires e Oliveira, 2014, p. 41-42). A despeito de essa literatura específica empregar o termo burocrata, optamos neste artigo por nos manter mais próximos ao vocabulário da saúde coletiva, dando preferência à palavra 'trabalhador'.

Assim, nossa análise é uma tentativa de lançar luz sobre a discricionariedade (Lotta e Santiago, 2017) presente no trabalho dos apoiadores, buscando compreender a forma de construção de relações institucionais desde a base do Estado brasileiro, com base no estabelecimento de determinadas dinâmicas relacionais entre sujeitos que ocupam funções públicas. Partimos da hipótese de que a construção de tais dinâmicas constitui redes de sociabilidades nas quais se ancora, de modo sempre instável e singular, os modos de funcionamento institucional. O oximoro empregado no título do artigo, "Burocracia cordial", visa justamente expressar essa característica. Na linha do que defende Jessé Sousa (2015), não entendemos essa cordialidade como algo necessariamente negativo. “Ora, se todos somos 'cordiais', por que apenas quando estamos no Estado desenvolvemos as consequências patológicas dessa nossa 'herança maldita?" (Sousa, 2015, p. 21).

Esta é uma perspectiva analítica que compreendemos não ser extemporânea ao objeto do estudo, na medida em que os próprios textos de referência do MS afirmam que o AI

“implica num modo de participar da relação com os outros entes federados, para além das normas e da indução financeira, aprendendo com os efeitos, aprimorando a prática gestora, a partir da análise de resultados em grupos plurais e implicados positivamente com mudanças para melhoria do SUS" (Brasil, 2013, p.13). 


\section{A questão federativa brasileira e o papel dos entes federados}

As questões federativas dizem respeito à forma de organização do país e ao nível de autonomia de cada ente que o compõe, ou seja, cada nível de governo tem certas atividades sobre as quais toma as decisões finais. De acordo com Lima (2006), “o federalismo reparte a autoridade política do Estado (a soberania) e o exercício do poder (o governo) em múltiplos centros soberanos definidos geograficamente e coordenados entre si" (Lima, 2006, p. 28). No caso brasileiro, estamos falando especificamente da União, dos 26 estados, do Distrito Federal e de 5.570 municípios. Embora a autonomia dos territórios seja prevista na Carta Constitucional, a defesa desta autonomia nos níveis estadual e municipal varia em função dos interesses políticos dos governadores e prefeitos em cada momento específico. Contudo, independente das orientações e intenções dos governantes, a estrutura jurídica brasileira apresenta alguns desafios que ainda não foram solucionados. Um dos principais, sobre o qual a estratégia do AI tenta se debruçar, é o formato concorrente de maior parte das políticas sociais brasileiras. Segundo Arretche (2004), na Assembleia Nacional Constituinte, todas as propostas que combinavam a descentralização das atribuições com a descentralização dos recursos foram derrotadas.

Assim, qualquer ente federativo estava constitucionalmente autorizado a implementar programas nas áreas de saúde, educação, assistência social, habitação e saneamento. Simetricamente, nenhum ente federativo estava constitucionalmente obrigado a implementar programas nestas áreas (Arretche, 2004, p. 22).

Para a autora, esta especificidade inscrita na Constituição gera "superposição de ações; desigualdades territoriais na provisão de serviços" (Arretche, 2004, p. 22). De forma que, ao menos no caso da saúde, o governo federal tem tido o poder de formular, coordenar e, sobretudo, financiar as políticas de saúde que serão desenvolvidas em nível local, rompendo com a ideia de aproximação da gestão com a realidade dos cidadãos, um dos ideais da reforma sanitária. Nesta leitura, o governo federal não obriga os demais entes a aderirem a suas propostas, mas induz com incentivos financeiros para que isto aconteça, principalmente por meio de portarias ministeriais. A pesquisa nos chamou a atenção, neste sentido, para os meandros existentes entre as portarias e a adoção das práticas em âmbito local. Não se trata de um processo automático e imediato, pelo contrário, a tal indução envolve uma série de relações, pactuações, conversas, disputas e formas de convencimentos feitos por sujeitos no cotidiano da gestão. No entanto, ao se olhar a edição da portaria e a adoção da política pelos entes estaduais e municipais, perde-se do horizonte analítico todos os meandros que permi- 
tiram tal adoção. Como salienta Abrucio (2002, p. 23), deve-se compreender as relações federativas para além de "um simples cabo de guerra, as relações intergovernamentais requerem uma complexa mistura de competição, cooperação e acomodação".

Caminha-se, no Brasil, numa tênue linha que ora pende para a busca pela autonomia dos entes federados, ora para sua desresponsabilização, dilemas implicados na clássica combinação entre o princípio da autonomia e o princípio da interdependência. No caso da saúde, isto se materializa na afirmação de que os entes são solidários na garantia do direito à saúde (interdependência) ao mesmo tempo em que define (por normas infraconstitucionais) a divisão de atribuições entre os três entes federativos (autonomias). Pelo caráter cooperativo do federalismo brasileiro, a implantação do SUS ocorre com base na disposição de atores políticos para dialogar em arenas decisórias; assim, prefeitos, governadores e secretários de saúde têm disputado recursos e poderes concomitantes à "consolidação de espaços de negociação e pactuação de interesses - entre a sociedade e o Estado (Conselhos de Saúde) e entre os agentes federativos (Comissões e Conselhos de Gestores)" (Lima, 2006, p. 272). São diversos atores negociando permanentemente, em distintos espaços, os quais nem sempre dialogam entre si. O entrave aos avanços do SUS está justamente na falta de consenso e convergência entre esses atores, uma vez que a relação entre entes federados não tem caráter hierárquico, e o governo federal não pode realizar ações diretas, o que significaria a ruptura com o pacto constitucional. A aposta na criação de um lugar estratégico de diálogo via AI pelo MS pareceu indicar uma tentativa de 'tencionar por dentro', ao invés de 'tencionar por cima', no sentido de harmonizar as relações e traçar um vértice que oriente as práticas de saúde especialmente na $\mathrm{AB}$.

A existência de 5.570 municípios - dos quais mais de $68 \%$ tem menos de 20 mil habitantes e apenas 17 contam com mais de um milhão de habitantes -, com igual autonomia, mas com capacidades técnicas e financeiras divergentes, evidencia o tamanho do desafio. Esse quadro impõe ao governo central grandes desafios na consolidação do SUS e na coordenação nacional de suas políticas e seus programas estratégicos. Lima et al. (2011) ponderam sobre um duplo aspecto da aposta na municipalização como estratégia central da reforma sanitária: se, por um lado, “abre possibilidades de transformação da relação Estado e sociedade e de maior experimentação no campo das políticas públicas em nível local", por outro, lembram os autores, "a maioria dos municípios brasileiros (os de pequeno porte populacional) não tem arrecadação própria significativa e depende de transferências intergovernamentais de recursos" (Lima, 2011, p. 38).

O papel desse poder local ficou evidente na pesquisa, frente às diferentes realidades dos territórios, que atravessam permanentemente o trabalho 
dos apoiadores, incluindo as disputas partidárias. Isso se soma à compreensão equivocada de que os "governos locais possam equacionar sozinhos suas próprias dificuldades" o que contribui muito mais com a instauração de disputas do "que a conformação de estratégias e de instrumentos de parceria entre os governos" (Lima et al., 2011, p. 39). Assim, a estratégia do AI apresentase como um recurso que visa operar por dentro das estruturas já existentes, aumentando a intensidade e a qualidade do contato entre os entes federados. De acordo com Orlando et al. (2015) "pautado na legislação que dispõe sobre o SUS, o AI é um processo que viabiliza uma modificação e uma interação das ações e serviços dos entes federativos, possibilitando intervenções eficientes e eficazes no setor" (Orlando et al., 2015, p. 635). Neste sentido, pode-se compreender o trabalho realizado pelos apoiadores como uma espécie de "coordenação federativa" (Arretche, 2004; Abrucio, 2005), na medida em que buscam desenvolver políticas públicas de forma integrada entre os entes federativos, compartilhando decisões (Abrucio, 2005). Assim, a implantação do AI seria um modo de "enfrentar os modelos de gestão verticalizados e autoritários, originando uma concepção de formação, produção de conhecimento e cooperação técnica" (Orlando et al., 2015, p. 636). Neste mesmo sentido, Falleiro et al. (2014) afirmam que o AI surge "como opção contra-hegemônica frente aos modelos de gestão mais tradicionais marcados pela excessiva burocratização, pelo autoritarismo e pela tomada de decisão de forma verticalizada" (Falleiro et al., 2014, p. 25).

\section{Procedimentos metodológicos}

O estudo foi realizado na Coordenação Geral de Gestão da Atenção Básica do Departamento de Atenção Básica do Ministério da Saúde. Trata-se de um estudo qualitativo, entre os anos de 2015 e 2017, cujos dados foram coletados por meio de pesquisa documental, observação, entrevistas em profundidade e grupo focal.

O desenvolvimento do estudo foi baseado na proposta de Comunidade Ampliada de Pesquisa, dispositivo que visa à participação ativa dos trabalhadores nas etapas e produções de pesquisa, de forma a realizar o diálogo entre os saberes científicos e os saberes da experiência, com base na atividade do trabalho e das suas singularidades/subjetividades. Foram realizados 10 encontros coletivos, que abarcaram os grupos focais, discussões fundamentadas na leitura de artigos científicos e dois seminários de discussão dos resultados da pesquisa, conforme detalhado no Quadro 1. 
Quadro 1

\begin{tabular}{|cl|}
\hline \multicolumn{2}{|c|}{ Encontros coletivos - Comunidade Ampliada de Pesquisa. Brasília, 2017.} \\
\hline Encontro & Pauta \\
\hline $1^{\circ}$ & Apresentação da pesquisa \\
$2^{\circ}$ & Grupo focal sobre processo de trabalho do apoio na CGGAB. Pactuação da participação do grupo. \\
$3^{\circ}$ & Apresentação de sistematização inicial das discussões do grupo \\
$4^{\circ}$ & Grupo focal sobre processo de trabalho do apoio na CGGAB \\
$5^{\circ}$ & Grupo focal com apoiadores centralizados e coordenadores CGGAB \\
$6^{\circ}$ & Discussão de textos da revisão de literatura \\
$7^{\circ}$ & Treinamento introdutório no software Atlas.Ti \\
$8^{\circ}$ & Grupo focal com apoiadores descentralizados CGGAB \\
$9^{\circ}$ & Seminário de pesquisa entre os pesquisadores e trabalhadores do apoio para discussão da análise \\
$1^{\circ}$ & inicial dos achados. \\
\hline
\end{tabular}

Fonte: Os autores

CGGAB: Coordenação Geral de Gestão da Atenção Básica

No período do estudo a equipe da CGGAB era composta por 21 apoiadores centralizados, 7 descentralizados e 2 coordenadores. As entrevistas e os grupos focais foram realizados no local de trabalho dos profissionais após a assinatura do termo de consentimento livre e esclarecido, e seguiu perguntas disparadoras previamente definidas. No total, foram realizadas 17 entrevistas de apoiadores centralizados; 4 entrevistas com apoiadores descentralizados; 2 entrevistas com dirigentes; 2 grupos focais com os trabalhadores centralizados do apoio; e 1 grupo focal com apoiadores descentralizados.

Os documentos provenientes da coleta de dados (transcrições das entrevistas e grupo focal) foram inseridos no software Atlas.Ti, para qual criou-se uma unidade hermenêutica denominada 'Apoio Institucional'. Empregaram-se as seguintes nomenclaturas: AIC (apoiador institucional centralizado); AID (apoiador institucional descentralizado); e G (grupo focal). Após esta etapa, foram realizadas as leituras dos documentos e a codificação. Os codes, de acordo com a linguagem do software, representam as unidades de registro (palavra, tema ou 'núcleos de sentido' para representação de um conteúdo), que facilitam o encontro dos trechos das falas (quotations) dos entrevistados, relacionadas a determinado tema. No presente estudo, foram definidas as categorias e subcategorias de análise apresentadas no Quadro 2 a seguir.

Quadro 2

\begin{tabular}{|ll|}
\hline Categorias e subcategorias & \\
\hline Categoria & Subcategorias \\
\hline Perfil & Sexo e idade \\
& Tempo de trabalho na CGGAB \\
& Vínculo profissional com o MS \\
& Região de origem \\
& Experiências de trajetória ligadas à Graduação \\
Trajetória profissional & Trajetória profissional pregressa \\
& Influências da trajetória no exercício do apoio \\
& Inserção na CGGAB/DAB \\
& Motivação para o trabalho como Al \\
\hline
\end{tabular}


Continuação do Quadro 2

\begin{tabular}{|c|c|}
\hline \multirow[t]{3}{*}{ Formação/qualificação profissional } & Educação formal \\
\hline & $\begin{array}{l}\text { Competências para o trabalho como Al } \\
\text { Educação permanente no trabalho } \\
\text { Aprendizagem no trabalho }\end{array}$ \\
\hline & Gestão do conhecimento e da informação \\
\hline \multirow[t]{8}{*}{ Experiência do apoio institucional } & Organização do processo de trabalho - AIC \\
\hline & Organização do processo de trabalho - AID \\
\hline & Prescrição do trabalho do Al \\
\hline & Trabalho real do Al \\
\hline & Relação com a CGGAB (AID) \\
\hline & Relação Interfederativa \\
\hline & Relação Intraministerial (MS) \\
\hline & Relação Intrassetorial (DAB) \\
\hline \multirow[t]{3}{*}{ Apoio integrado } & Avanços possibilitados pelo Al \\
\hline & Ações desenvolvidas \\
\hline & $\begin{array}{l}\text { Histórico } \\
\text { Relação com o DAB/MS }\end{array}$ \\
\hline
\end{tabular}

Fonte: Os autores.

CGGAB: Coordenação Geral de Gestão da Atenção Básica; MS: Ministério da Saúde; DAB: Departamento de Atenção Básica; Al: apoiador institucional; AIC: apoiador institucional centralizado; AID: apoiador institucional descentralizado.

O presente artigo apresenta resultados obtidos por meio da subcategoria 'relações federativas', composta por 218 citações. A análise do material nos permitiu construir um arcabouço teórico-conceitual que busca traçar um quadro mais nítido do trabalho dos apoiadores institucionais nas relações federativas. O manuseio deste material foi feito com base na perspectiva da análise de conteúdo (Bardin, 2006), o que nos levou a identificar três categorias analíticas que constituem os elementos estruturantes do trabalho de AI na $\mathrm{AB}$ e a construir uma tipologia das estratégias de atuação dos apoiadores no contexto das relações federativas.

A pesquisa passou pelo comitê de ética em pesquisa com o registro CAAE: 34349314.4.0000.5650. Todos os trechos de fala citados estão codificados em AI (quando se refere à entrevista realizada com apoiadores institucionais) e GF (quando se refere a falas retiradas de grupos focais), seguidos por numeral arábico que indica a ordem de sua realização.

\section{Contexto da pesquisa}

Embora tenhamos localizado na introdução do artigo o surgimento da estratégia do AI na gestão do SUS, é importante contextualizarmos sua configuração na gestão federal, no momento de realização da pesquisa. Destaca-se que entre a escrita do projeto e a entrada no campo ocorreram diversas transformações no interior do MS que alteraram significativamente o AI. Como não dispusemos de acesso a registros e memória institucional sobre essas alterações, precisamos, necessariamente, recorrer aos relatos dos entrevistados para tentar ressaltar os traços mais relevantes do contexto da experiência estudada. 
Pode-se dizer que a experiência inicia-se com a primeira eleição do presidente Lula que significou, entre outras coisas, um importante movimento no sentido de democratização da gestão pública no Brasil. No âmbito da saúde, destaca-se, por exemplo, a criação da SGEP, a configuração do Colegiado do MS, e a elaboração do Plano Nacional de Saúde (2004-2007). É neste contexto, conforme apresentado na introdução, que o AI surge como estratégia no âmbito do MS, notadamente no âmbito da PNH.

Com a gestão do ministro Alexandre Padilha, já no governo da presidente Dilma Rousseff, houve uma mudança na orientação política do MS em relação ao papel do AI. Para além de uma atuação por dentro de uma política específica, o AI passou a ser empregado como estratégia central na articulação interna do ministério. Neste momento, a inserção do AI passou a contar com muito mais força, tanto financeira, quanto política. Como já dito, o AI surgiu então com o objetivo de reconfigurar a relação do governo federal com estados e municípios, tornando-se uma estratégia de gestão que envolvia todas as secretarias do MS. No entanto, após a imensa aposta feita pelo MS no papel central do AI, essa mudança não chegou a se institucionalizar de fato, pois em 2014 o Apoio Integrado foi desarticulado, em um processo associado ao fim do Projeto de Formação e Melhoria da Qualidade das Redes de Saúde QualisUS, ao qual estava vinculado.

Desta forma, entre 2011 e 2013, houve um grande movimento dentro do MS em que as diferentes secretarias começaram a contratar apoiadores descentralizados, incluindo o DAB. Contudo, os dados da pesquisa mostraram que, ao contrário desse movimento maior que vinha ocorrendo no MS, o DAB compreendeu a atuação dos apoiadores de forma distinta. Sua inserção na dinâmica do apoio integrado revelou-se tangencial. Por outro lado, os apoiadores tornaram-se atores centrais na indução e na disseminação de pautas prioritárias do departamento, como o Requalifica-UBS, o E-SUS, e o Programa de Melhoria do Acesso e da Qualidade na Atenção Básica (PMAQ-AB). Pode-se dizer que a implantação da estratégia do apoio integrado em âmbito ministerial não orientou a forma como o apoio foi organizado e operado pelo DAB.

$\mathrm{O}$ uso diferenciado do AI pelo DAB talvez tenha relação com o fato da ampliação da Atenção Primária ter se constituído como agenda estratégica para o governo. Por se tratar de política que necessariamente implica numa relação mais harmônica entre os entes, especialmente em função da necessidade do estabelecimento de uma relação cooperativa de financiamento e condução das políticas pelos municípios, o AI foi usado] como aposta central para realizar esta articulação. 


\section{A tal indução do Ministério da Saúde e o papel das pessoas}

Iniciamos nosso percurso analítico retomando a ideia difundida na literatura sobre a 'indução', para expressar a busca pela efetivação das políticas de saúde propostas pelo MS e implementadas pelos estados e municípios. Evidentemente, apenas a edição de uma norma não é suficiente para que a política se materialize nos diversos entes federados. A pesquisa realizada demonstra que é o trabalho humano, realizado, no caso aqui estudado, pelos apoiadores institucionais, o responsável pela pavimentação das vias que ligam as normas às práticas.

Os resultados obtidos revelam que tal pavimentação ocorreu com a mobilização de determinados atributos pessoais e que não são esperados pela análise social brasileira, porque sempre associados a um estado pré-moderno. Como bem aponta Jessé Souza (2015), essa é uma compreensão que tende a demonizar o Estado brasileiro. O autor nos apresenta uma outra possibilidade de compreensão da sociabilidade brasileira em que a assimilação da falsa oposição entre mercado e Estado serve apenas aos interesses da elite, na medida em que na história do Brasil qualquer avanço para as classes mais pobres sempre esteve associado à atuação do Estado e não do mercado. É neste sentido que a proposta de democratizar a gestão do SUS por dentro, num contexto de tentativa de democratização mais ampla do Estado brasileiro, pelo governo Dilma Rousseff, é uma tarefa fundamental, mas repleta de dificuldades e contradições.

A análise do material empírico nos levou a identificar dois elementos estruturantes do trabalho dos apoiadores sem os quais dificilmente teriam obtido sucesso: vínculo e conhecimento do território. Tais elementos subsidiaram a construção de uma tipologia da estratégia de atuação dos apoiadores, que visa dialogar tanto com a ideia clássica de indução do MS, quanto com a perspectiva federativa já comentada de Abrucio (2002), segundo a qual “as relações intergovernamentais requerem uma complexa mistura de competição, cooperação e acomodação". Com base na análise do material empírico, propomos compreender o trabalho dos apoiadores nas relações federativas orientado por três estratégias desenvolvidas por eles próprios, a depender do contexto, pois são os indivíduos "que interpretam as regras, valores, expectativas e esperanças quando tomam as decisões para as quais foram contratados" (Lotta e Santiago, 2017, p. 26): a primeira das três estratégias é a cooperação; a segunda é a adaptação; e, por último, a aplicação. “Analisar o papel dos indivíduos e suas compreensões e sentimentos sobre os processos de implementação torna-se, portanto, central para observar o que valorizam no processo de tomada de decisão" (Lotta e Santiago, 2017, p. 26). 


\section{Elementos estruturantes do trabalho dos apoiadores institucionais}

Propomos pensar vínculo e conhecimento do território como elementos estruturantes do trabalho dos apoiadores, em função tanto do que está presente na literatura, quanto pela força com que tais atributos emergiram na fala dos sujeitos da pesquisa. Além disso, tais características se reforçam mutuamente, sendo a divisão aqui proposta de caráter puramente teórico. A presença física dos apoiadores nos territórios propicia momentos de escuta sobre suas necessidades, contribuindo com o estabelecimento de vínculo e confiança, e também com o conhecimento do apoiador sobre aquela realidade. Os achados apresentados neste artigo dialogam com o referencial teórico metodológico sobre AI, na medida em que nele é destacado o caráter relacional inerente às práticas de produção de saúde. A constituição de modos de vinculação entre os sujeitos é fundamental para a eficácia do trabalho em saúde, seja na perspectiva da atenção, como nos processos de sua gestão e organização. É neste sentido que os autores referidos compreendem a cogestão, na qual a construção de redes de confiança opera como uma dimensão fulcral.

\section{Vínculo}

Ao analisarmos as relações federativas no âmbito da $A B$, no período estudado, fica clara a importância da dinâmica relacional e presencial entre sujeitos. O desenvolvimento de políticas e programas de saúde acaba sendo o resultado da incorporação do instrumento normativo mediado por relações humanas em que o vínculo e a confiança são aspectos centrais. Klitzke (2013, p. 45) ressalta que "o apoio pauta-se na crença de que tal processo envolve os sujeitos em suas experiências concretas de relações cotidianas". A questão do contato pessoal foi apontada pela maior parte dos entrevistados como central na condução do trabalho de AI. Há um reconhecimento explícito de que o "mandato institucional só funciona porque se estabelece a partir de uma relação pessoal" (GF 2) e de que a relação institucional melhora muito quando se conhece pessoalmente o outro.

Com rosto, com nome, é mais do que só a voz no telefone (AI 9).

Outro apoiador corrobora essa perspectiva ao afirmar que

o encontro presencial ajuda muito porque as pessoas sabem quem você é, veem que você é de carne e osso. Quando você conhece as pessoas, quando você tem uma conversa, você tem um momento mais informal com essas pessoas, acho que facilita bastante (AI 4). 
Barros, Guedes e Roza (2001, p. 4.805) defendem que o AI é “um tipo de tecnologia relacional" que, no caso estudado, tem repercussões de diversas ordens, especialmente no que diz respeito ao contato pessoal.

O vínculo é uma categoria clássica na saúde, que se refere frequentemente às relações estabelecidas entre profissionais de saúde e usuários dos serviços. Aqui, no entanto, ela deriva da construção de relações estabelecidas sobretudo presencialmente, desde os espaços de encontro entre profissionais da gestão, qualificando a relação entre pessoas de instituições diferentes. A existência de vínculos prévios à atuação como apoiador surge como uma ferramenta facilitadora do trabalho a ser desenvolvido.

O vínculo é fundamental, se você tem vínculo prévio, fica muito mais fácil, que foi o caso do estado X (AI 20).

Paulon, Pasche, Righi (2014) ressaltam que a existência de vínculo e de confiança diferencia o apoio substancialmente "de outras possibilidades de encontro, como visitas, participação em capacitações ou atualizações" (Paulon, Pasche e Righi, 2014, p. 813). Maerschner et al. (2014) ressaltam outros aspectos das relações estabelecidas pelos apoiadores que são fundamentais na criação de vínculos pois, segundo os autores, constituem-se como relações de mão dupla, nas quais residem "solidariedade, troca de experiência, encontro de saberes e subjetividades" (Maerschner et al., 2014, p. 1.094).

A existência de 'confiança' (aspecto subjetivo nas relações interpessoais) parece ser um elemento fundamental no estabelecimento desse vínculo.

Tem que existir uma confiança. Confiança dos municípios, dos estados, do município com o apoiador para poder deixar a relação forte (AI 10),

$\mathrm{O}$ vínculo é fundamental, porque ele leva à confiança. Então assim, muitas vezes que eu precisei ser mais dura, principalmente em questões políticas (...). Não é só o vínculo, pelo vínculo. Ah!, eu te conheço, você é minha amiga! Mas o vínculo de poder saber que eu estou aqui porque eu sou técnica e porque eu quero ajudar, porque eu quero fazer alguma coisa melhorar. E conhecer você também, qual é o teu olhar sobre isso? Se você também tem interesse que a coisa ande, ou se você está indo só pelo teu emprego (AI 16).

O trecho destacado traz para dentro do Estado atributos e valores que em geral são tidos pelo senso comum como próprios da esfera do mercado: confiança e seriedade no trabalho. O apoiador destaca ao lado da existência do vínculo o lugar do profissional técnico, o que significa dizer que o trabalho não é feito apenas por relações pessoais, mas dentro de um contexto técnico e ético que busca a qualidade das ações e ofertas públicas, e que é mediado, aí sim, por dinâmicas relacionais entre os sujeitos. Em termos éti- 
cos ressaltamos que o trabalho dos apoiadores é a evidência de que "existem sujeitos/trabalhadores comuns, comprometidos, que optaram por se engajar em uma luta para a construção e consolidação de um SUS melhor" (Cassella e Machado, 2018, p. 808).

\section{Conhecimento do território}

A literatura tem apontado como fundamental no trabalho do apoiador a "construção de autonomia dos sujeitos [nos territórios], desde definição a execução das políticas de saúde em conformidade com suas necessidades e características locorregionais" (Souza, 2014, p. 28). Como identificar, no entanto, quais as necessidades e características locais? Os apoiadores afirmam que

o território é que demanda, o território é que mobiliza, o território é que faz a gente fazer as coisas, não somos nós, muito menos o ministro, é o território (AI 20).

Este reconhecimento exige dos apoiadores um trabalho singular, específico para cada contexto

porque o contexto de um lugar é diferente do outro, você tem essa relação mais próxima, consegue entender e ver que talvez precise usar outros instrumentos, até as ferramentas são diferentes de um lugar para outro (GF1).

Carvalho et al. (2013) destacam a necessidade de se "diminuir a fragmentação da agenda estratégica do SUS" com base no reconhecimento das "singularidades dos contextos locais". Neste sentido, observamos que o trabalho do apoiador revelou-se efetivamente como um recurso para "potencializar uma maior horizontalidade e cooperação nas relações interfederativas" (Carvalho et al., 2013, p. 4).

\section{Tipologia das estratégias de atuação dos apoiadores}

A análise do material empírico e a leitura da discussão específica sobre as questões federativas nos levaram a aprofundar o conhecimento sobre o papel dos apoiadores na coordenação federativa, especialmente na tarefa de indução das políticas nacionais. O trabalho de AI encontra-se ancorado na premissa de que os entes são autônomos, não havendo uma proeminência da União sobre estados e municípios, por isso a necessidade do MS de induzir as políticas públicas do setor. Neste sentido, é possível dizer que a indução no trabalho dos apoiadores se desenvolveu com base em três sentidos, os quais variaram historicamente e podem se confundir em função das especificidades locais. 
Como qualquer construção teórica, esta tipologia não se apresenta como uma tentativa de abarcar os detalhes de toda a realidade, mas tão somente visa apresentar os principais traços do fenômeno estudado. Esta análise se relaciona com a discussão realizada por Lotta e Santiago (2017) de autonomia dos burocratas, na medida em que são eles mesmos que decidem a forma de relacionamento que estabelecerão com cada território, tendo por base a dinâmica relacional e o conhecimento do contexto. "Apesar de diferentes aspectos determinarem a liberdade de que o burocrata dispõe para agir, entender como os burocratas atuam é outra dimensão do estudo sobre o conceito" (Lotta e Santiago, 2017, p. 24). Neste sentido, estamos buscando novos elementos que contribuam para a compreensão sobre as formas de atuação desses trabalhadores.

Inicialmente, identificamos a indução como aplicação, a qual diz respeito a uma forma de atuação dos apoiadores que tem relação com o modo de coordenação tradicional e verticalizado do MS, que caracterizou historicamente a gestão federal, e é amplamente descrito na literatura. Chama a atenção que esta nunca foi a estratégia buscada prioritariamente pelos apoiadores, mas, sobretudo, por muitos municípios que, por baixa capacidade de gestão, buscavam o caminho mais rápido para a chegada dos recursos, abrindo mão, muitas vezes, da possibilidade de construção de um percurso de implementação de políticas e programas mais adequado a suas realidades. Nestes casos, portanto, não eram as necessidades de saúde que estavam sendo tomadas como definidoras dos rumos das políticas públicas, mas tão somente qualquer aporte financeiro que pudesse beneficiar a imagem pública do gestor local.

Em segundo lugar, parte do trabalho ocorreu em função da adaptação das expectativas federais aos contextos locais. Diversos relatos mencionam a existência de políticas federais com financiamento previsto que, embora pertinentes à realidade local, ainda encontravam barreiras para implantação. Isto é efeito também da dimensão continental do país e de suas significativas heterogeneidades regionais. Uma mesma política não é passível de ser implementada da mesma forma em contextos diferentes. Nestes casos, o trabalho dos apoiadores consistia em buscar compreender o contexto e as estratégias mais pertinentes para a implementação. Diferente do tipo anterior, este pressupõe abertura e diálogo entre os sujeitos que tocam o dia a dia do SUS no Brasil.

Eles olham, "isso aqui não tem nada a ver, não condiz com a minha realidade"; e aí eu me deparo com uma portaria que na gestão anterior tinha sido formulada, publicada e tal, e nenhuma adesão à portaria. [...] E aí eu comecei a saga, tem que entrar num barco, tem que entrar numa voadeira, tem que ver que a gente fica 7 dias de barco para chegar numa comunidade para ver que essa portaria não se aplica. Estou te dando esse exemplo para dizer que o apoio institucional qualificou essa formulação... (AI 3). 
No trecho destacado o apoiador ressalta a importância do sujeito local ao dizer "vocês precisam conhecer a realidade lá para vocês verem que isso não se aplica". A adaptação funciona, portanto, como uma estratégia importante para lidar com as imensas diferenças entre as realidades locais, e depende da capacidade de diálogo entre os apoiadores e os sujeitos que vivem as especificidades dos territórios. O relato chama a atenção para uma transição da postura de aplicação, passando pela adaptação e mostrando o caminho para o próximo tipo: cooperação.

Este terceiro tipo representa um estágio bem avançado de construção de políticas entre entes federados, pois pressupõe, além da abertura para o diálogo, o estabelecimento de um objetivo comum, que nos relatos dos apoiadores passava pela construção conjunta da agenda de trabalho e pela tentativa de transformação da forma de gerir os serviços de saúde. Nestes casos, a construção da agenda de trabalho dos apoiadores partiu do objetivo de unificação das pautas dos entes federados. Souza (2014) ressalta que no trabalho do apoiador

há uma construção da política de saúde a partir da indução federal, mas também da acolhida do apoiador para as necessidades do território. As relações do conjunto de apoiadores tendem a ser horizontais na busca pela qualidade da política de saúde, considerando os sujeitos, o território apoiado e a produção da cogestão (Souza, 2014, p. 30).

Orlando et al. (2015, p. 637) também destacam a busca pelo estabelecimento de "afinidades e vínculo entre as três esferas de governo" como uma característica do trabalho do apoiador. Um dos entrevistados caracterizou o trabalho como uma tentativa de "constituição de uma relação federativa mais orgânica" (AI 11).

A construção de tal agenda é característica das estratégias de adaptação e de cooperação, e têm como fundamento o estabelecimento de dinâmicas relacionais entre sujeitos, conforme descrito na seção anterior. Parte da organização do processo de trabalho do apoiador pauta-se na oferta de políticas, na tentativa mesmo de indução para incorporação de determinadas ações e serviços no sentido da aplicação. Souza (2014) também chama a atenção para essa característica, pois, se de um lado estão as "demandas e frentes prioritárias da Gestão Federal", de outro, deve-se atentar para a "demanda do próprio território. Isso provocava uma tensão para o apoiador (...) Essa é uma das principais atuações dos apoiadores, a mediação de conflito e a decisão junto aos entes..." (Souza, 2014, p. 34). Um entrevistado reconhece essa tensão, mas a coloca no âmbito do próprio trabalho dos apoiadores na medida em que estes ampliam o horizonte de atuação dos territórios. 
Eu acho que a gente era muito demandado. Muito, muito. É... Inclusive a distância pelos municípios e tal. Mas uma boa parte dessa demanda ela era provocada pelas ofertas (AI 19).

Essa relação entre demanda e oferta no trabalho dos apoiadores indica a forma como o trabalho é desenvolvido. Um entrevistado analisa que quanto mais distante do território (fisicamente), mais se trabalha apenas dando respostas às demandas dos territórios. Para ele, a presença física no território permite apresentar um conjunto de outras possibilidades que "por telefone é mais difícil".

O apoio institucional agrega elementos que eu acho importantes, o apoio institucional diz: "olha, o território é que demanda aquilo que de fato ele precisa, se você quer ajudar alguém, você não pode vir com encomenda, você tem que escutar primeiro", isso a gente aprende no apoio institucional. Então o apoio institucional me ajudou a fazer essa relação federativa, que já é estabelecida, se tornar melhor e mais fluida (AI 20).

A valorização da escuta representa uma transformação importante na história da gestão federal (verticalizada) no setor saúde, na medida em que apresenta a tentativa de migrar do sentido da aplicação para os outros dois sentidos sistematizados.

Um dos objetivos explícitos da estratégia do AI em sua atuação nas relações federativas é a tentativa de ampliar a capacidade de gestão dos estados e municípios. Há uma sincronia, neste caso, com o documento do MS sobre o apoio à gestão descentralizada do SUS, que afirma que o apoio deve buscar “estabelecer relações construtivas entre as três esferas de governo, funcionando como um dispositivo de apoio à gestão e fortalecimento da capacidade de governo sobre o sistema de saúde nos âmbitos estadual e municipal" (Brasil, 2004, p. 10). Além disso, percebe-se que o trabalho realizado pela CGGAB visava “(...) usar a estratégia do apoio institucional para estabelecer relação com estados e municípios" (AI 18).

Ou seja, não se tratava apenas de contribuir para o desenvolvimento da capacidade de gestão, posto que derivava disso a necessidade de se construir melhores relações entres os entes. Melo (2015) destaca que no contexto da atenção básica o apoiador tem buscado "a reformulação do modo tradicional de se fazer gestão, disparando processos instituintes e promovendo suporte a movimentos de mudanças, alicerçados na democracia institucional e autonomia dos sujeitos" (Melo, 2015, p. 148). Segundo um apoiador,

quando você vai no território, você discute com o gestor: Qual atenção básica que você quer? Que tipo de serviço você quer oferecer? O que você pretende? Então, 
a gente fomenta isso na gestão municipal. Essa discussão dele repensar o papel dele (AI 14).

Tal diálogo evidencia a estratégia de cooperação que vimos destacando.

Essa estratégia gerou um efeito não esperado pelo MS que foi o estabelecimento de uma relação direta entre governo federal e os municípios. Buscavase, ao contrário, o fortalecimento do papel dos estados, entes federados que foram se colocando à parte do processo de construção do SUS:

O foco maior do apoio eram as secretarias estaduais de saúde, tanto pelas pernas, que a gente não teve perna para apoiar os municípios, quanto por um entendimento de que talvez não coubesse a gente querer apoiar a gestão municipal diretamente. Que isso caberia mais ao estado fazer (AI 19).

A relação direta com os municípios acabou sendo uma externalidade (sob o ponto de vista dos entrevistados) dos vínculos criados e da relação de confiança que passou a se constituir entre as pessoas à frente da gestão da $\mathrm{AB}$. Em função de tais dinâmicas relacionais entre sujeitos propusemos o oximoro que nomeia este artigo. A cordialidade aqui é uma forma de interpretar as relações estabelecidas em função da institucionalidade inerente a tais relações. Entendemos esta cordialidade como algo positivo que qualifica o contato entre os atores.

Como afirmou um dos entrevistados: "Às vezes o município não procura o estado. Ele vem direto para cá, né?" (AI 8). Tal busca direta indica o reconhecimento da capacidade técnica e de resolução dos AIs, ao mesmo tempo que evidencia a compreensão do papel restrito que os entes estaduais vêm tendo na condução das políticas de saúde. As entrevistas corroboram certo vazio de gestão deixado por este ente. Para um apoiador, uma parte das demandas que o MS recebe diretamente dos municípios "tem a ver com uma certa incapacidade ou dificuldade das secretarias estaduais darem um suporte para os municípios..." (AI 19).

Outro entrevistado percebe, com base em sua experiência, que

grande parte das secretarias tem uma certa crise de identidade, uma certa dificuldade de saber qual é seu lugar, enfim, saber em tese, mas não conseguir operar (AI 18).

Uma terceira fala relevante neste sentido aponta que "especialmente nos municípios pequenos o pedido de apoio técnico aos estados é gigantesco. E são poucos que conseguem de fato fazer" (AI 13). 
Diante de diferentes demandas, dos mais variados municípios, é absolutamente razoável pensar que as estratégias de atuação dos apoiadores passem pelos três tipos aqui construídos.

Outro aspecto fundamental no trabalho dos apoiadores que transita pelos tipos adaptação e cooperação é a busca pela construção da relação com os territórios de forma individual e horizontal. É possível afirmar que o conjunto dos relatos converge no sentido de afirmar que "não existem receitas" (AIC 8) para o estabelecimento das relações federativas. Que tipo de trabalho fazer? Como fazer? Que relações estabelecer? Tais questões não são passíveis de serem respondidas antes que o trabalho comece. Diefenthaeler (2014) também apontou, em sua pesquisa, que o apoiador institucional necessita buscar “construir horizontalmente a relação da gestão federal com os estados e municípios" (Diefenthaeler, 2014, p. 41). Essa ideia de horizontalidade aparece diversas vezes nos relatos.

Tem uma relação de poder aí, gestão federal, quem repassa mais recursos, estadual e municipal, acho que essa relação horizontal é a chave para você quebrar isso ou, minimamente, compartilhar poder, se mostrar disponível (Gl).

Acho que essa relação horizontal é essencial, independente de ser apoio institucional ou não, qualquer outro tipo de terminologia ou conceito de gestão que a gente vá fazer, para mim isso é essencial se mostrar disponível (Gl).

Essa característica dialoga com o argumento que desenvolvemos anteriormente de que a base da relação federativa tem sido construída pelos apoiadores em função das dinâmicas relacionais entre sujeitos, especialmente as presenciais.

Por fim, destacamos a existência dos conflitos político-partidários como uma característica que tem grande interferência na atuação dos apoiadores e que acaba sendo determinante no tipo de estratégia a ser adotada. Encontramos referência à questão político partidária nos artigos de Borges (2013) e Ribeiro (2013). Esses dois autores apontaram para a diminuição da autonomia dos municípios na condução das políticas sociais do governo federal na medida em que tais políticas constituíram-se como elementos centrais na disputa eleitoral à Presidência da República. Na pesquisa por nós empreendida a questão partidária ganha relevância em função de sua frequência no relato dos apoiadores e pelo modo como interferiu em várias experiências concretas que foram relatadas.

Essa questão partidária é muito importante. Dependendo se o estado se for aliado ou não do governo federal, você tem entrada ou não. Porque ele acha que o Ministério da Saúde (...) está indo para monitorar e não para contribuir (AI 14). 
Como relatou um entrevistado

a linha entre o conflito absoluto e a uma parceria relativa é muito tênue para aquele estado, por conta de uma série de fatores, inclusive, político, e principalmente, talvez, o político (AI 15).

Além disso, um relato chama a atenção para tentativas de boicote das políticas federais por parte de estados com partidos de oposição.

A gente ouve alguns municípios relatarem de credenciamento de equipe, resolução que tem que passar pelo estado demorar de sair (...), porque partido oposto. Entendeu? Têm estados que fazem isso... (AI 14).

Um outro relato chama a atenção para o fato de que existem conflitos que não necessariamente relacionam-se ao fato de o governo ser de oposição, mas, ao contrário, pela expectativa de alcançar benefícios por ser aliado: “Alguns são aliados, e por serem aliados, acham que devem ser beneficiados. E também não dão muita entrada" (AI 14).

No termos de Lotta e Santiago (2017, p. 36), a questão político-partidária apesar de não ser parte explícita das 'regras' institucionais, é uma 'condição' que atua como empecilho institucional para a autonomia dos AIs. A análise das três estratégias de relacionamento estabelecidas entre os AIs e os trabalhadores das outras esferas de gestão nos aproxima da discussão realizada por estes autores a respeito da discricionariedade enquanto ação, na medida em que os elementos que buscamos para explicar os caminhos para a implantação de políticas federais nos contextos locais incorpora tanto a "forma como os burocratas interpretam as regras e implementam políticas públicas" quanto “aspectos do indivíduo, como julgamentos, valores políticos, papel social, dentre outros" (Lotta e Santiago, 2017, p. 36).

\section{Considerações finais}

Propusemos, neste texto, o oximoro burocracia cordial, o que nos leva a duas considerações importantes sobre o processo analisado. Em primeiro lugar, o avanço da implantação da estratégia de AI foi possível, fundamentalmente, em decorrência das dinâmicas relacionais estabelecidas entre os sujeitos e da discricionariedade inerente a suas funções, na busca por relações institucionais perenes e democráticas. Isto, contudo, traz consigo uma dificuldade de manutenção ou replicação da estratégia, tanto porque o período de experiência foi interrompido bruscamente, com a iminente queda do governo Dilma Roussef e a reforma ministerial realizada em 2015, e talvez não tenha 
tido tempo suficiente para transformar as relações por dentro, como esperado; quanto porque a baixa institucionalidade dos quadros técnicos - muitos dos apoiadores não eram servidores públicos - não permita tal perenidade na burocracia brasileira.

A luta pela democratização da gestão pública passa pelo necessário fortalecimento do Estado brasileiro, o que pressupõe a existência de sujeitos empenhados com este projeto. O contexto nacional atual (escrevemos em janeiro de 2019) denota exatamente o oposto do fortalecimento do Estado. Temos assistido ao desmonte de históricas conquistas de cidadania e proteção social, que permitiriam trilhar um caminho mais propenso à democracia e à participação. Analisamos neste artigo um contexto que não existe mais, uma aposta que foi desfeita, um Estado que foi desfigurado. Nossa reflexão se concentrou nas ações realizadas por sujeitos no interior do Estado brasileiro, e é justamente o papel deste Estado que está em xeque atualmente. Hoje, a luta pela democracia e pela saúde se confunde com a afirmação do protagonismo do Estado nas políticas sociais. Os resultados encontrados com a pesquisa indicam possibilidades concretas de avanço na garantia do direito à saúde, não obstante as dificuldades e contradições que caracterizam nossas relações federativas. Neste cenário, o lema "democracia é saúde, saúde é democracia" adquire novo sentido, pois atinente não apenas a horizontes almejados, mas a avanços já realizados, cujos frutos dependem intrinsecamente dessa relação.

\section{Colaboradores}

Os três autores participaram da concepção, condução da pesquisa e da escrita do artigo.

\section{Financiamento}

A pesquisa foi financiada com recursos da Chamada Universal MCTI/CNPq n.14, de 2014. 


\section{LA BUROCRACIA CORDIAL: LA IMPLEMENTACIÓN DE LA ESTRATÉGIA DE APOYO INSTITUCIONAL EN LA POLÍTICA NACIONAL DE ATENCIÓN BÁSICA EN SALUD}

Resumen El artículo analiza el papel de los apoyos institucionales como sujetos responsables por la conducción de las políticas públicas. Busca, de ese modo, comprender la forma de construcción de relaciones institucionales desde la base del Estado brasileño, mediante el establecimiento de dinámicas de relación entre agentes públicos, especialmente en el enfrentamiento de las complejas cuestiones sobre las relaciones federativas brasileñas. El estudio fue realizado en la Coordinación General de Gestión de la Atención Básica, del Departamento de Atención Básica del Ministerio de la Salud. Configura una búsqueda surgida en la epistemología cualitativa, con la realización de búsqueda documental, observación, entrevistas en profundidad y grupos focales entre noviembre de 2015 y junio de 2017. Los resultados permitieron la identificación de dos elementos estructurantes del trabajo de los apoyos - vínculo y conocimiento del territorio -, los cuales subsidiaron la construcción de una tipología de la estrategia de actuación desarrollada y operada por los apoyos, a saber: aplicación, adaptación y cooperación. Se concluye que el avance de la implementación de la estrategia de apoyo institucional fue posible fundamentalmente en función de la dinámica de relación y presencial entre sujetos, y sus resultados indican posibilidades concretas de avance en la garantía del derecho a la salud, no obstante las dificultades y contradicciones que caracterizan el federalismo brasileño.

Palabras clave atención primaria de salud; gestión en salud; organización y administración; federalismo; burocracia.

\section{Referências}

ABRUCIO, Fernando L. Descentralização e Coordenação Federativa no Brasil: lições dos anos FHC. 2002. Disponível em: <http://antigo. enap.gov.br/downloads/ec43ea4fTextoFernandoAbruciolDescentraliza.pdf $>$. Acesso em 10 out. 2018.

ABRUCIO, Fernando L. A coordenação federativa no Brasil: a experiência do período FHC e os desafios do governo Lula. Revista de Sociologia e Política, Curitiba, n. 24 , p. 41-67, 2005.

ARRETCHE, Marta. Federalismo e políticas sociais no Brasil: problemas de coordenação e autonomia. São Paulo Perspectiva, São Paulo, 2004 , v. 18, n. 2, p.17-26.

BAPTISTA, Tatiana W. F. Análise das portarias ministeriais da saúde e reflexões sobre a condução nacional da política de saúde.
Cadernos de Saúde Pública, Rio de Janeiro, v. 23, n. 3, p. 615-626, 2007.

BARDIN, Laurence. Análise de conteúdo. Lisboa: Edições 70, 2006.

BARROS, Maria E. B.; GUEDES, Carla R.; ROZA, Mônica M. R. O apoio institucional como método de análise-intervenção no âmbito das políticas públicas de saúde: a experiência em um hospital geral. Ciência \& Saúde Coletiva, Rio de Janeiro, v. 16, n. 12, p. 4.803-4.814, 2011.

BORGES, André. Eleições presidenciais, federalismo e política social. In: HOCHMAN, Gilberto; FARIA, Carlos A. P. Federalismo e politicas públicas no Brasil. Rio de Janeiro: Editora Fiocruz, 2013. p. 121-150.

BRASIL. Ministério da Saúde. Secretaria Executiva. Departamento de Apoio à Descentra- 
lização. Apoio integrado à gestão descentralizada do SUS: estratégia para a qualificação da gestão descentralizada. Brasília: Ministério da Saúde, 2004.

BRASIL. Ministério da Saúde. Secretaria-Executiva. Caderno de referência para o processo de formação de profissionais do apoio institucional integrado do Ministério da Saúde: QUALISUSREDE. Brasília: Ministério da Saúde, 2011.

BRASIL, Ministério da Saúde. Diretrizes do apoio integrado para qualificação da gestão e da atenção no SUS. Brasília: Ministério da Saúde, 2013. 49 p.

CAMPOS, Gastão W. S. O anti-Taylor: sobre a invenção de um método para co-governar instituições de saúde produzindo liberdade e compromisso. Cadernos de Saúde Pública, Rio de Janeiro, v. 14, p. 863-870, 1998.

CAMPOS, Gastão W. S. Um método para análise e co-gestão de coletivos a constituição do sujeito, a produção de valor de uso e a democracia em instituições: o método da roda. 2. ed. São Paulo: Hucitec, 2005.

CASSELLA, Nélida A.; MACHADO, Felipe R. S. Apoio Institucional: a percepção dos apoiadores em uma maternidade pública de Alagoas. Trabalho, Educação e Saúde, Rio de Janeiro, v. 16, n. 2, p. 799-820, 2018.

CARVALHO, André L. B. et al Apoio Integrado como estratégia de Cooperação Interfederativa no SUS. In: CONGRESSO BRASILEIRO DE POLÍTICA, PLANEJAMENTO E GESTÃO EM SAÚDE, 2. Belo Horizonte: Abrasco, 2013. Disponível em: <http://www.politicaemsaude. com.br/anais/trabalhos/publicacoes/062.pdf $>$. Acesso em: 12 jan. 2018.

DESLAURIERS, Jean-Pierre; KERISIT, Michèle. O delineamento de pesquisa qualitativa. In: POUPART, Jean et al. A pesquisa qualitativa: enfoques epistemológicos e metodológicos. Petrópolis: Editora Vozes, 2014. p.127-153.

DIEFENTHAELER, Sibeli S. A flor e a náusea no Apoio Institucional: o processo histórico de organização do Apoio Institucional na CGGAB/ DAB/MS. 2014. 47 f. Trabalho de Conclusão de Curso (Especialização) - Universidade Federal do Rio Grande do Sul, Rio Grande do Sul, 2014.

FALLEIRO, Letícia M. et al. Considerações preliminares sobre Apoio Institucional e Educação Permanente. In: FALLEIRO, Letícia. M. (org.). Experiências de Apoio Institucional no SUS: da teoria à prática. Porto Alegre: Rede Unida, 2014. p. 19-30.

KLITZKE, Dirceu D. Apoio institucional na gestão da atenção básica no Brasil: um caminho possível? 2013. $80 \mathrm{f}$. Dissertação (Mestrado em Saúde Coletiva) - Pós-graduação em Saúde Coletiva da Universidade de Brasília, 2013.

LIMA, Luciana D. Federalismo, relações fiscais e financiamento do Sistema Único de Saúde: a distribuição de receitas vinculadas à saúde nos orçamentos municipais e estaduais. 2006. $409 \mathrm{f}$. Tese (Doutorado em Saúde Coletiva) - Instituto de Medicina Social da Universidade do Estado do Rio de Janeiro, Rio de Janeiro, 2006.

LIMA, Luciana D. et al. O Pacto Federativo Brasileiro e o Papel do Gestor Estadual no SUS. In: UGÁ, Maria. A. D. et al (org.). A Gestão do SUS no âmbito estadual: o caso do Rio de Janeiro. Rio de Janeiro: Editora Fiocruz, 2011. p. 27-58.

LOTTA, Gabriela; SANTIAGO, Ariadne. Autonomia e discricionariedade: matizando conceitos-chave para o estudo de burocracia. BIB, São Paulo, n. 83, p. 21-42, 2017.

LOTTA, Gabriela S.; PIRES, Roberto R. C.; OLIVEIRA, Vanessa E. Burocratas de médio escalão: novos olhares sobre velhos atores da produção de políticas públicas. Revista do Serviço Público, Brasília, v. 65, n. 4, p. 463-492, 2014.

MAERSCHNER, Rosane L. et al. Apoio institucional: reordenamento dos processos de trabalho: sementes lançadas para uma gestão indutora de reflexões. Interface: Comunicação, 
Saúde, Educação, Botucatu, v. 18, sup. 1, p. 1.089-1.098, 2014.

MELO, Lygia M. F. Apoio Institucional em saúde: desafios para democratização na Atenção Básica. 2015. 175 f. Tese (Doutorado em Saúde Coletiva) - Universidade Federal do Rio Grande do Norte, Centro de Ciências da Saúde, Natal, 2015.

OLIVEIRA, Gustavo N. Devir apoiador: uma cartografia da função apoio. 2011. 175 p. Tese (Doutorado em Saúde Coletiva) - Faculdade de Ciências Médicas, Universidade Estadual de Campinas Faculdade de Ciências e Letras de Assis, Universidade Estadual Paulista, Campinas, 2011.

ORLANDO, Cláudia R. P. et al. Apoio Institucional: potencialidades e desafíos. Revista Eletrônica Gestão \& Saúde, Brasília, v. 6, n.1, p. 633-649, 2015.
PAULON, Simone M.; PASCHE, Dário F.; RIGHI, Liane B. Função apoio: da mudança institucional à institucionalização da mudança. Interface: Comunicação, Saúde e Educação, Botucatu, v.18, sup. 1, p. 809-820, 2014.

RIBEIRO, Leandro M. Federalismo, governo local e políticas sociais no Brasil entre 1996 e 2004. In: HOCHMAN, Gilberto; FARIA, Carlos A. P. Federalismo e politicas públicas no Brasil. Rio de Janeiro: Editora Fiocruz, 2013. p. $151-178$.

SOUZA, Bruna C. Apoio institucional: o processo de trabalho do apoiador na coordenação geral de da atenção básica: potencialidades e desafios para a condução e operacionalização da política de atenção básica. 2014. 45 f. Trabalho de Conclusão de Curso (Especialização), Universidade Federal do Rio Grande do Sul, Brasília, 2014.

SOUZA, Jessé. A tolice da inteligência brasileira: ou como o país se deixa manipular pela elite. Rio de Janeiro: LeYa, 2015. 